\title{
Effect of Macro Factor Volatility on the Returns of Financial Sector in Southeast Asian Stock Markets
}

\author{
Siriwun Wongsrida, Prasert Chaitip \\ Chiang Mai University, Chiang Mai, Thailand
}

\begin{abstract}
The emphasis of this study is on the practice of the Pooled Mean Group (PMG) estimators to investigate the magnitude of macroeconomic performances: Real Gross Domestic Product (RGDP), Foreign Exchange Rate (EX), and Deposit Interest Rate (DINT) affecting on the rate of financial sector returns in Southeast Asian Stock Markets including Stock Exchange Of Thailand (SET) index (Thailand), the Kuala Lumpur Composite Index (KLSE) index (Malaysia), Financial Times Share Index (FTSI) (Singapore), Philippine Stock Exchange (PSE), and the Jakarta Composite Index (JKSE) (Indonesia). The Panel Autoregressive Distributed Lag (Panel ARDL) is applied to model the relations. The study applies the Levin, Lin, and Chu (LLC) test (2002) and Im, Pesaran, and Shin (IPS) test (2003) to investigates a set of time series data to examine whether the determinants and the rate of financial sector returns contain a unit root, the next step is investigated the cointegration and causality relationship of the determinants of financial sector influencing on long-run rate of returns of financial sector in Southeast Asian Stock Markets.
\end{abstract}

Keywords: rate of returns, financial sector, Southeast Asian Stock Markets, panel unit root, Panel Autoregressive Distributed Lag (Panel ARDL)

\section{Outcome Predictions in Legal Decision Making}

Five Southeast Asian Stock Markets are recovering from the global financial crisis due to a powerful stimulus to the various ASEAN government taking steps to restore confidence in the demand of the market and stabilize the financial markets. As a result, ASEAN grew 1.5 percent in 2009 and expected to grow at 4.9 to 5.6 percent in 2010, moving forward, the challenge for ASEAN is to sustain the economic recovery by using monetary policy. Appropriate macroeconomic policy reforms and strengthening agencies have been in place since the financial crisis in Asia, 1997-1998 (Retrieved from www.asean.org), because the capital markets of the countries in the region are relatively small. The collaboration aims to promote the growth of Southeast Asian Stock Markets by streamlining ASEAN Exchanges access, introducing cross-border harmonization. The ASEAN Exchanges collaboration will bring greater economic opportunities to more people as well as bring greater capital liquidity to collaboration Southeast Asian members.

ASEAN Exchanges is an important footstep in the collaboration of Southeast Asian capital markets to create opportunities. The investment will be transferred among five Southeast Asian Stock Markets (RM)

Siriwun Wongsrida, M.A., Faculty of Economics, Chiang Mai University.

Prasert Chaitip, Ph.D., Associate Professor, Faculty of Economics, Chiang Mai University.

Correspondence concerning this article should be addressed to Prasert Chaitip, Faculty of Economics, Chiang Mai University, Chiang Mai, Thailand. E-mail: wongsrida.anna.8@gmail.com; nnfunction@gmail.com. 
covering SET index (Thailand), KLSE index (Malaysia), FTSI index (Singapore), PSE and JKSE index (Indonesia), driven in the financial sector. Due to the establishment of Asean Economic Community (AEC) by 2020, capital flows aimed at further promotion of investment in Southeast Asian member economies.

This study attempts to investigate the order of integration panel unit root tests and the Panel ARDL relationship between the rate of financial sector returns in Southeast Asian Stock Markets (RM), and magnitude of selected macro-economic performance including Gross Domestic Product (GDP), EX and DINT from 2003 to 2012 using. The statistical results can also be useful tools as information to facilitate dialogue of decision-making processes developed in Southeast Asian Stock Markets.

\section{Theory and Hypothesis}

\section{The Efficient Markets}

The efficient markets theory proposed by Fama (1970) is a proposition that the prices of stocks, bonds, and other securities fully reflect all available information at any point in time. This is the result of profit-maximizing investors painstakingly searching for information and using what they know, including what they think will happen in the future, when trading securities. Active trading moves prices until the risk-adjusted expected returns are equal for all securities. Further changes are due to events not known beforehand, which are quickly built into prices. In an efficient market, investment capital is allocated to its most productive use. Market efficiency also implies that investors cannot "beat the market" or find securities that are mispriced such that their portfolios consistently perform better than the market.

To observe Southeast Asian Stock Markets, the first subject is to understand the determinants of the rate of returns of financial sector in Southeast Asian Stock Markets (RM) covering the annual statistical reports of RGDP, EX, and DINT. However, ASEAN Exchanges' national-level panel data are used to analyze the influencing factors on Southeast Asian Stock Markets (RM). Literatures based on the macro data used the ARDL model to be tested. Because the ARDL model completely depended on the statistical relationship, any change in sample interval will cause the instability of the results.

\section{Suggests that Market Effectively: Diagrammatic Design for Investment in Southeast Asian Stock Markets}

The market efficiency can reflect the information of investors. Investors receive information on the changes to affect the stock price which would have to turn down as well (see Figure 1).

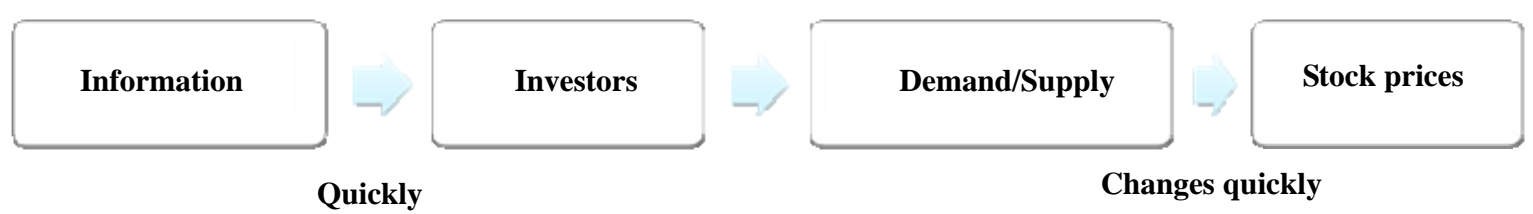

Figure 1. Diagrammatic design for investment in Southeast Asian Stock Markets.

\section{Research Framework}

This study will establish the theoretical framework by the Diagrammatic Panel ARDL Approaches shown in Figure 2.

The practice of the Pooled Mean Group (PMG) estimators was conducted to investigate the magnitude of macroeconomic performances: Real Gross Domestic Product (RGDP), Foreign Exchange Rate (EX), and 
Deposit Interest Rate (DINT) affecting on the rate of financial sector returns in Southeast Asian Stock Markets.

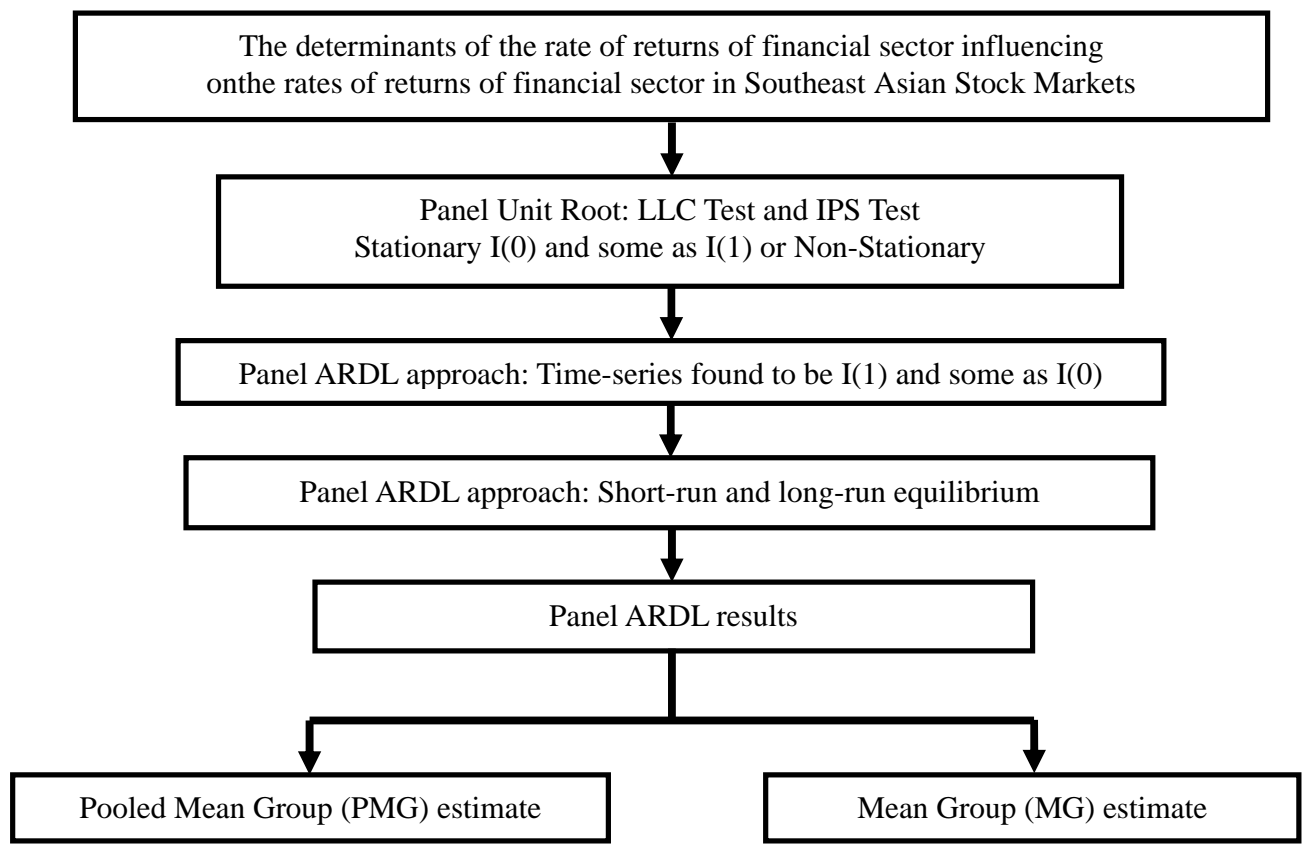

Figure 2. Diagrammatic panel ARDL approach and hypotheses.

\section{Research Subject}

This paper aims to experiment impulse mechanism of interaction between the rate of the returns of financial sector (RM) and macroeconomic fundamentals using Southeast Asian Stock Markets' panel data of five main countries stretching from 2003 to 2012. Panel ARDL data were utilized to test whether the recognized statistical relationships' exist among different Southeast Asian member economies on the rate of financial sector returns in Southeast Asian Stock Markets. To estimate the effects of each explanatory variable of the rate of financial sector returns including SET index (Thailand), KLSE index (Malaysia), FTSI index (Singapore), PSE and JKSE index (Indonesia), and economic panel ARDL models were adopted.

\section{Panel Unit Root}

This study applies panel unit root tests instead of traditional unit root tests to increase testing power from additional information provided by the pooled cross-section time series. Prior to PMG estimators' analysis, panel root tests are required to determine the order of integration of the variables (Mahyideen, Ismai, \& Hook, 2012). In this study, implement two panel unit root tests and different yet popular tests: LLC (2002) test with common unit root process and IPS (2003) test with individual unit root processes were tested. The LLC test is a based on homogeneity of the autoregressive parameter (Das, Chowdhury, \& Muhammad, 2012), and involves fitting an Augmented Dickey Fuller (ADF) regression for each panel to estimate the coefficient $\alpha$ from the proxies. The test is based on the following regression.

$$
\Delta y_{i t}=\alpha y_{i t-1}+\sum_{j=1}^{\rho_{i}} \beta_{i t} \Delta y_{i t-j}+X_{i t-j}^{\prime} \delta+\varepsilon_{i t}
$$

While the IPS test is based on heterogeneity of the autoregressive parameters (Das et al., 2012), the test is also modified by using ADF test. Equation (1) is fitted to each panel cross section. 
The results from Table 1 show the panel unit root test of variables used in the study. The results from the LLC test at stationary level or I(0) explain that a set of panel data between the rate of financial sector returns in Southeast Asian Stock Markets (RM) and Macro Factor Volatility evidence that EX and DINT variables are non-stationary at level or I(0). All variables are stationary at the first difference or I(1) significant at 0.01 level. The results of the unit root test using the IPS test show that all variables are non-stationary at level or I(0). When taking all variables into consideration, RM, RGDP, EX, and DINT, they all are stationary at the first difference or I(1). RGDP and EX at significant level of 0.01, and RM and DINT at significant level of 0.1.

Table 1

Results Panel Unit Root

\begin{tabular}{llcll}
\hline Level or I $(0)$ & \multicolumn{3}{c}{ 1st difference or I(1) } \\
\hline Variables & LLC & IPS & LLC & IPS \\
\hline $\ln R M$ & $-2.77^{* * *}$ & 0.03 & $-4.48^{* * *}$ & $-1.64^{*}$ \\
$\operatorname{lnGDP}$ & 1.15 & 1.90 & $-25.36^{* * *}$ & $-8.29^{* * * *}$ \\
$\ln$ XX & $-2.86^{* * *}$ & -1.19 & $-12.84^{* * *}$ & $-6.38^{* * *}$ \\
$\ln I N T$ & 1.50 & 1.62 & $-4.27^{* * *}$ & $-1.62^{*}$ \\
\hline
\end{tabular}

Notes. ${ }^{* * *},{ }^{* *}$, and ${ }^{*}$ imply levels significance at $1 \%, 5 \%$, and $10 \%$, respectively.

To sum up, both LLC test and the IPS test indicated that a set of panel data between the rate of financial sector returns in Southeast Asian Stock Markets (RM) and Macro Factor Volatility evidence that EX and DINT variables are stationary at the first difference or I(1), though at different degree of stationary; the Pooled Mean Group Estimation allows us to use variables at different levels of stationary (Pesaran, Shin, \& Smith, 1999).

\section{The MG and PMG Estimations}

PMG estimation of dynamic heterogeneous panels proposed by Pesaran et al. (1999) investigates the factors affecting a set of panel data between the rate of financial sector returns among five Southeast Asian Stock Markets (RM). PMG method is an intermediate estimator because estimation of dynamic heterogeneous panels involves both pooling and averaging (Pesaran et al., 1999). The method constrains the long-run coefficients to be equal over the cross-sections, but allows for the short-run coefficients and error variances to differ across cross-sections. The results indicate obtain pooled long-run coefficients and averaged short run error correction dynamics as an indication of mean reversion (Barrell \& Davis, 2004).

The PMG is based on an ARDL $(p, q, \ldots, q)$ model. Suppose that given data on time periods $t=1,2, \ldots, T$ and groups $i=1,2, \ldots, N$ and the dependent variable $y$ is:

$$
y_{i t}=\sum_{j=1}^{p} \lambda_{i t} y_{i, t-j}+\sum_{j=0}^{q} \delta_{i j}^{\prime} x_{i, t-j}+\mu_{i}+\varepsilon_{i t}
$$

where it $x_{i t}(k \times 1)$ is the vector of explanatory variables for group $i, \mu_{i}$ represents the fixed effects, the coefficients of the lagged dependent variables $\lambda_{i j}$ are scalars and $\delta_{i j}$ is $k \times 1$ coefficient vectors. $T$ must be large enough so that the model can be estimated for each cross section.

The re-parameterization form of equation (2) can be formulated as follows:

$$
\Delta y_{i}=\phi_{i} y_{i,-1}+\beta_{i}^{\prime} x_{i t}+\sum_{j=1}^{p=1} \lambda_{i j}^{*} \Delta y_{i, t,-j}+\sum_{j=0}^{q=1} \delta_{i j}^{*} \Delta x_{i, t,-j}+\mu_{i}+\varepsilon_{i t}
$$

It is assumed that the disturbances $\varepsilon_{i t}, i=1,2, \ldots, N, t=1,2, \ldots, T$ in equation (3) are independently distributed across $i$ and $t$, with zero means, variances $\sigma_{i}^{2}>0$ and finite fourth moments. This assumption 
ensures that $\phi_{i}<0$, the roots of equation (3) must lie outside the unit circle. Thus, there exists a long-run relationship between $y_{i t}$ and $x_{i t}$ which is defined by

$$
y_{i t}=-\left(\beta_{i}^{\prime} / \phi_{i}\right) x_{i t}+\eta_{i t}
$$

The long-run homogeneous coefficient is equal to $\theta_{i}=\beta_{i}^{\prime} / \phi_{i}$, which is the same across groups. For our purpose, the key feature of the PMG is to make the long-run relationships while allowing for the heterogeneous dynamics and error variances (Barrell \& Davis, 2004).

Hausman tests of the difference between Mean Group (MG) estimator and PMG estimator of the long-run coefficients were settled and PMG estimator compared with the MG estimator. The main MG and PMG results produce dissimilar computed output results given in Table 2. The PMG provide consistent estimates with the theory. Pesaran et al. (1999) argued that MG estimator is always consistent. For comparison of the MG and the PMG both testing for a null hypothesis of a unit root against the alternative, a Hausman test was used to determine the consistency of an explicit estimator of common coefficients. The p-values associated with PMG estimators reject the null hypothesis of no long-run relationship. In PMG model, long-run rate of returns financial sector by macroeconomic factor volatility is determined. The finding of MG estimator suggests a positive and insignificant coefficient of lnRGDP. The study shows stationary in first difference or I(1) of macro-economic performance. Additionally, the essential characteristics of an experiment with Panel ARDL model estimation based on PMG and MG aimed to investigate the empirical relevance of observing long-run equilibrium properties. The empirical results confirm the presence of long-run equilibrium relationships between pairs of macroeconomic factors and rate of returns of financial sector in Southeast Asian Stock Markets.

Table 2

Presents the Major MG and PMG Results Derived From Southeast Asian Stock Market Model

Dependent variable: $\operatorname{lnRM}$

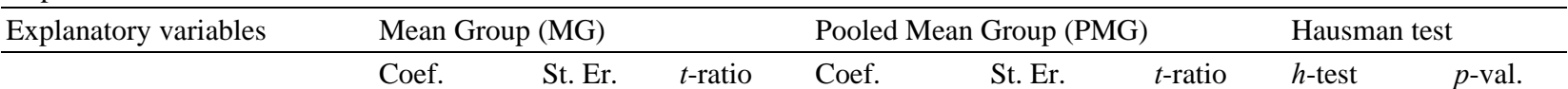

Long run coefficients

\begin{tabular}{lcccccccc}
$\ln R G D P_{i t}$ & -78.226 & 91.337 & -0.856 & $3.288^{* * * *}$ & 0.225 & 14.597 & 0.8 & 0.37 \\
$\ln E X_{i t}$ & -0.665 & 1.459 & -0.456 & $-0.05^{* * *}$ & 0.013 & -3.773 & 0.18 & 0.67 \\
$\ln D I N T_{i t}$ & -0.004 & 0.223 & -0.019 & $-0.074^{* * *}$ & 0.016 & -4.626 & 0.1 & 0.76 \\
Short run coefficients & & & \multicolumn{7}{c}{ Joint Hausman test: } & & 4.89 & 0.18 \\
$\ln R G D P_{i t}$ & -4.469 & 14.404 & -0.31 & $3.551^{* * *}$ & 0.425 & 8.36 & \\
$\ln E X_{i t}$ & 0.179 & 0.429 & 0.418 & $-0.054^{* * *}$ & 0.006 & -8.36 & \\
$\ln D I N T_{i t}$ & 0.01 & 0.09 & 0.114 & $-0.08^{* * *}$ & 0.01 & -8.36 \\
$\Delta \ln R G D P_{i t}$ & 11.447 & 10.729 & 1.067 & 7.364 & 5.717 & 1.288 & \\
$\Delta \ln E X_{i t}$ & -0.483 & 0.357 & -1.352 & -0.059 & 0.076 & -0.781 & \\
$\Delta \ln D I N T_{i t}$ & $-0.114^{*}$ & 0.065 & -1.758 & -0.017 & 0.02 & -0.879 & \\
Error correction & $-0.94^{* * *}$ & 0.31 & -3.033 & $-1.08^{* * *}$ & 0.129 & -8.36 & \\
Constant & 0.554 & 5.878 & 0.094 & $-1.312^{*}$ & 0.879 & -1.493 &
\end{tabular}

Notes. ${ }^{* * *},{ }^{* *}$, and ${ }^{*}$ imply levels significance at $1 \%, 5 \%$, and $10 \%$, respectively.

According to computed output results among five Southeast Asian Stock Markets, statistical techniques with Panel ARDL model estimation based on PMG confirmed that a change in percent of RGDP was statistically significant positive long-run equilibrium properties with a change in percent of long-run rate of 
returns financial sector. There is strong macro factor volatility evidence that EX and DINT variables were statistically significant negative long-run equilibrium properties with a change in percent of long-run rate of returns financial sector. The computed output results among five Southeast Asian Stock Markets established a short-term relationship based on Panel ARDL causality method to explore the direction of error correction term equals to -1.080 at significant level of 0.01 .

\section{Conclusions}

This study investigates the short-run and long-run relationships between rate of return on financial sector index among five ASEAN Exchanges, using the annual statistical reports of RGDP, EX, and DINT from 2003 to 2012. The results of the panel unit root test indicated that all variables are stationary at the first difference or I(1) at first different degree of stationary. Using PMG, there is strong unidirectional causality running from Macroeconomic factors for the five Southeast Asian Stock Markets samples. Lastly, in an attempt to analyse the short-run and long-run causality between Macroeconomic factor volatility and rate of financial sector returns, the results indicated the existence of directional short-run causality from Macroeconomic factors, thus emphasizing the view, embodied in the ruling that long-run rate of returns financial sector is determined by Macroeconomic factor volatility.The possibilities of short-run adjustment can be considered among five Southeast Asian Stock Markets based on Panel ARDL causality method to explore the direction of error correction term equals to -1.080 at significant level of 0.01 .

\section{References}

Barrell, R., \& Davis, E. P. (2004). Consumption, financial and real wealth in the G-5. London: NIESR and Brunel.

Das, A., Chowdhury, M., \& Muhammad, A. (2012). Panel cointegration and pooled mean group estimation of energy-output dynamics in South Asia. Journal of Econometric and Behavioral Studies, 4(5), 277-286.

Fama, E. F. (1965). Random walks in stock market prices. Financial Analysts Journal, 21(5), 55-59.

Fama, E. F. (1970). Efficient capital markets: A review of theory and empirical work. Journal of Finance, 25, 383-417.

Levin, A., Lin, C., \& Chu, C. J. (2002). Unit root in panel data: Asymptotic and finite sample properties. Journal of Econometric, $108,1-24$.

Mahyideen, J. M., Ismai, N. W., \& Hook, L. S. (2012). A pooled mean group estimation on ICT infrastrure and economic growth in ASEAN-5 countries. Journal of Econometric and Management, 6(2), 360-378.

Ndambendia, H., \& Njoupouognigni, M. (2010). Foreign aid, foreign direct investment and economic growth in Sub-Saharan Africa: Evidence from pooled mean group estimator (PMG). International Journal of Economics and Finance Research, 2(3), 39-45.

Pesaran, M. H., Shin, Y., \& Smith, R. P. (1999). Pooled mean group estimation of dynamic heterogeneous panels. Journal of the American Statistical Association, 94(446), 621-634. 